\title{
Do Transformational Leaders Engage Employees in Sustainable Innovative Work Behaviour? Perspective from a Developing Country
}

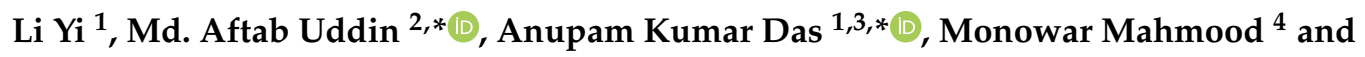 \\ Shanewaz Mahmood Sohel ${ }^{2}$ \\ 1 School of Management, Shanghai University, Shanghai 200444, China; liyi@shu.edu.cn \\ 2 Department of Human Resource Management, University of Chittagong, Chattogram 4331, Bangladesh; \\ sohel@cu.ac.bd \\ 3 Department of Management, University of Chittagong, Chattogram 4331, Bangladesh \\ 4 Bang College of Business, KIMEP University, Almaty 050010, Kazakhstan; monowar@kimep.kz \\ * Correspondence: mdaftabuddin@cu.ac.bd (M.A.U.); dasanupam@cu.ac.bd (A.K.D.)
}

Received: 11 March 2019; Accepted: 24 April 2019; Published: 28 April 2019

\begin{abstract}
Inadequate and inconclusive studies of the role of transformational leadership (TL) on employee creative process engagement (CPE) and sustainable innovative work behaviour (IWB) have motivated the authors to further advance knowledge in this aspect of the workplace. In doing so, the present study seeks to extend the understanding of innovative work behaviour by the involvement of TL and its subordinates through engaging employees in the creative process. The authors adopted the deductive reasoning approach to measure the observed relationships using structural equation modelling (SEM) through SmartPLS 2, a second-generation integrated regression model for statistical measurement. The results from self-report and others' reported questionnaires reveal that transformational leaders can engage their subordinates in the creative process and sustainable innovative outcomes by influencing employee intrinsic motivation and proactive behaviour. However, the mediating effect of CPE on TL and IWB is not supported. Lastly, the authors discuss the findings and contributions of these empirical findings in theory and practice. In addition to the potential implications of the examined results, this study also recommends directions for further research in the light of its limitations.
\end{abstract}

Keywords: transformational leadership; creative process engagement; sustainable innovative work behaviour; intrinsic motivation; proactive behaviour; developing country

\section{Introduction}

The past century has witnessed dynamic changes in competition, globalisation in the workforce, the internationalisation of business and its operations, and information and communication technology [1]. These issues demand that business enterprises creatively engage in their activities to survive the competition by providing innovative solutions [2,3]. In effect, research on creativity and innovation has experienced robust growth in the last few decades [4]. Recent studies shed light on employees' autonomy, motivation, and engagement in accelerating creative efforts [5-7]. However, in most of the studies, creativity is conceptualised as an outcome of a creative effort, and the creative process engagement (CPE) component, which precedes the creative outcome, is ignored [8,9]. With the interplay of the CPE's constituents, such as problem identification, information search, encoding, and idea generation, employees generate creative ideas to resolve the prevalent problems in the organisation $[8,10,11]$. Until recently, little has been known about CPE's contribution to sustainable innovative work behaviour (IWB) due to the limited literature $[8,10]$. Studies have claimed that 
employees, when led by a supportive [12] and non-controlling leader, such as a transformational leader, exert creativity in doing things $[8,13]$. Therefore, the organisation needs transformational leadership (TL) to foster employees' proactive behaviour and CPE to propel a sustainable innovative organisation in the long run so that competitiveness is assured.

The componential theory of creativity posits this as the outcome of individual creative skills, expertise, and intrinsic motivation [14-16]. Conversely, we have focused on CPE and sustainable IWB based on the model of individual creative action, wherein Ford [17] states that employees get to choose from two competing options to be creative: either to deviate from routine work [18] or to be conventional [19]. This model shows that creative action is the product of sense-making processes, motivation, knowledge, and ability [20]. Thus, the current study presumed that IWB and CPE are the decisions of individuals, given that TL allows its followers to assume more flexibility and responsibility [21-23].

Despite the conspicuous importance of CPE and sustainable IWB to organisational competitiveness, we observed that previous studies have a Westerner-bias. Very little if any attention is paid to developing countries and Eastern cases [4]. Negligible studies have been conducted in developing and South Asian nations, including Bangladesh $[24,25]$. The theory of individual creative action focuses on solving an existing problem by combining ability and motivation with creative action [17]. According to the theory of individual creative action, creative engagement leading to sustainable innovative behaviour can be possible elsewhere if contexts have a capable individual with the requisite motivation along with a clear goal to solve the prevailing problem. Henceforth, it is very likely that developing countries might also overcome their situation and display creative actions, as mentioned by Ford [17], an idea largely ignored in previous studies. TL, a contextual predictor of innovation, ensures an atmosphere for a person-organisation fit by engaging individuals in the creative process $[26,27]$.

Therefore, empirically, this paper hopes to contribute to the literature on under-developed and developing countries in many ways. First, the extant literature includes a good number of studies on creative or innovative behaviour; however, little is known about engagement in the creative process that precede the creative outcome [4,28]. Second, we observed that prior studies focus mostly on innovative behaviour or creative performance and very little on CPE. Interestingly, we have found no study that connects CPE to IWB. Thus, the present study on sustainable IWB through potential direct and mediating variables will advance preconceived knowledge of the extant literature about the reciprocal understanding of the predictor variables of $\mathrm{CPE}$ and sustainable IWB. Third, numerous studies on CPE and innovation shed light on doing research in developed countries, as most studies seem to be Western-biased. Hence, some studies have urged future researchers to conduct their work in different contexts, particularly in developing countries, as opposed to those examined in previous studies $[4,11,29]$. The present study, conducted in Bangladesh, an Asian emerging/developing country, will strengthen previous findings. Lastly, previous studies have been heavily criticised for drawing inferences on their generalisability and for over-inflating their results, either because of self-report surveys [30] or other report surveys [31] or because replies were collected from a single organisation [11]. Thus, in line with suggestions from Podsakoff, et al. [32], Gupta, Singh and Bhattacharya [31], and Zhang and Bartol [10], we used both report survey methods to avoid bias from self-response or other responses.

\section{Theory and Development of Hypothesis}

\subsection{Transformational Leadership}

There has been exponential growth in the literature on TL-related studies since the ideation by Burns [33], which was later extensively studied by Bass [34]. TL is the ability to inspire and empower employees to navigate their self-interests for the enhancement of the organisation and to have a profound and extraordinary effect on followers. TL drives individuals towards a desired destiny by displaying personalised behaviour and a shared vision [22,24,29]. A transformational leader 
empowers them in questioning the status quo and challenges and stimulates them to think outside of the box by engaging them in divergent thinking rather than in being compliant [28]. Seamless support of the employees' constructive deviances transforms these traits into self-determination and independence, which build the foundation for being a creative when facing the unforeseeable future. Likewise, employees led by TL engage in a creative process that is informal, less routinised, and unconventional $[4,28]$. Essentially, TL exhibits its deep-seated faith in the abilities of followers and allows them to engage in creative involvement towards innovative pursuits.

\subsection{Creative Process Engagement and Sustainable Innovative Work Behaviour}

Creativity is the production of novel and useful ideas (i.e., product, process, procedure, methods, or anything) either in the short term or long term [21]. On the other hand, creative behaviour refers to the creation of noble and useful ideas, and sustainable IWB is meant as the development of ideas and implementation of those ideas into improved phenomena or outcomes to prolong benefits $[3,14,35]$. In CPE, employees engage, expose, and express themselves cognitively, emotionally, physically, and behaviourally in their workplace $[4,9,36]$. CPE refers to employees' involvement in the related creative process, such as problem construction and development, information searching and encoding, and alternative idea generation. Henceforth, sustainable IWB refers to prolonging the creative outcome and the results that emanate from employees' engagement in the creative process. CPE is crucial to sustainable IWB because it is the pre-requisite for creativity (generating noble and useful ideas). We have used sustainable IWB in the sense that these innovative behaviours must be maintained at a certain level or continue over a long period of time to become competitive. Innovative work behaviour is the intentional and voluntary work behaviour of the employees directed towards implementing or introducing new ideas, methods, processes, and procedures into their work units developed through employees' creative process engagement.

\subsection{Mediation Effect of Intrinsic Motivation}

The theory of TL delineates that TL attributes, through the demonstration of individualised consideration and inspirational motivation, navigate the intrinsic motivation of employees [29]. A strong conviction of TL on employees' capability makes their jobs enjoyable and interesting, which stimulates them to engage in non-traditional, non-routinised, and creative activities [4]. Engagement in the creative process requires an employee to be a challenge-taker and intrinsically motivated. When people are involved in creative processes (e.g., problem identification, information searching and encoding, and idea generation), they engage themselves very critically and spend a large amount of time generating noble and useful solutions for identified problem areas [29]. Thus, intrinsically motivated employees require that the characteristics of the job and its surrounding organisational support, i.e., TL, engage in creative initiatives [15]. They tend to be independent, risk-takers, self-determined, non-routinised, flexible, and competent, which are the key ingredients for generating creative ideas $[37,38]$. Thus, intrinsic motivation facilitates the effect of TL on CPE $[15,39,40]$. Therefore, the literature review provides the foundation for Hypothesis 1.

Hypothesis 1 (H1). Intrinsic motivation mediates the relationship between transformational leadership and creative process engagement.

\subsection{Mediation Effect of Proactive Behaviour}

Given the ideation of TL, it can be postulated that TL has a compelling impact on employee proactivity, since it improves their creative self-efficacious belief to apply what they believe will improve the organisation $[8,41]$. By cultivating a fair climate, TL empowers employees to act from their own initiative and take responsibility by their own discretion. In addition, TL provides real-time feedback and constructive suggestions during employees' engagement in the creative process. Zhang, et al. [42] show that when employees with distinctive proactivity come across supportive leaders with 
the same behaviour, their proactivity increases. The proactive behaviour appears to build a trustworthy relationship between the pair, which assists employees in obtaining the necessary information on emerging problems and opportunities, and feedback to better address them. Liu and Shi [43] state that employee proactivity is change-oriented and self-initiated and does not passively wait for an opportunity to be offered to them by others. Its extroversion behaviour tends to exhibit autonomy and ambition, which eventually leads to engagement in the creative process [44]. Thus, it is very likely that employees with proactive behaviour will actively engage in problem identification, search and encode information, and generate ideas. Accordingly, the following hypothesis can be set:

Hypothesis 2 (H2). There is also a mediation effect of proactive behaviour on the relationship between transformational leadership and creative process engagement.

\subsection{Mediation Effect of Creative Process Engagement}

Employees with TL are intrinsically motivated to engage in proactive behaviour, which in effect leads to creative engagement and sustained innovative behaviour $[10,11,14,38,45,46]$. The extant literature contains many studies supporting the linkage between intrinsic motivation and IWB $[14,15,45]$. Amabile $[14,15]$ shows that employees' intrinsic motivation plays a significant role in their behavioural decision-making, which is conducive to leading to a sustainable innovative outcome. Thomas [47] states that intrinsically motivated employees are prone to contribute to and engage in such unusual work behaviour, depending on how the organisation and their leader (i.e., TL) support them. The study showed that the impact of intrinsic motivation on sustainable IWB is evident, and other researchers have extended the findings that IWB can be more streamlined given the creative engagement of intrinsically motivated employees [11,47]. Accordingly, we can propose the following hypothesis.

Hypothesis 3 (H3). CPE mediates the relationship between intrinsic motivation and sustainable innovative work behaviour.

Likewise, Liu and Shi [43] mention that employee proactivity is change-oriented and self-initiated and that employees never wait for the opportunity to be presented to them by others to become proactive. They keep working on identifying opportunities, act on them, take further action, and persist until the desired change is accomplished [48]. Proactivity is difficult to define. Crant [49], for example, states the following: "I define proactive behaviour as taking the initiative in improving current circumstances or creating new ones; it involves challenging the status quo rather than passively adapting to present conditions." These people also seem intrinsically motivated $[37,38,49]$. Several empirical investigations have shown that proactivity is positively related to creative and innovative behaviour [44,50,51]. Gong, et al. [52] reinforce the effect of proactivity on creative outcome by focusing on the employees' engagement in information exchange and trust in their workplace. They reveal that employees' creative engagement through information exchange and knowledge-sharing induces trust and confidence, which in turn fosters their creative outcome. Moreover, proactive employees engage in unconventional actions when the organisation offers them a chance to do so, and they proactively seek out new information and ways of improving matters [50]. Several studies indicate that proactivity discharges creative or innovative behaviour by creative engagement only when the recruiting organisation maintains a secure working environment [50-52]. To summarise, the study proposes Hypothesis 4 .

Hypothesis 4 (H4). Creative process engagement mediates the relationship between proactive behaviour and sustainable innovative work behaviour.

An organisational climate and the role of TL have been increasingly used to initiate intrinsic motivation, proactivity, and IWB $[6,39,53]$. Globally, research shows that TL has a profound contextual impact on an employee's innovative and creative performance [54,55]. Amabile [14] claims that intrinsic 
motivation alone is not sufficient for creativity and innovation in the organisation. He further underlines that engaging employees in the creative process engagement has an equal chance, if not the best chance, of enhancing IWB. Although leaders in organisations play a minimal role in dealing with creative employees $[4,56,57]$, TL can contribute to restructuring the work and the working environment so that issues surrounding problem identification, information search and encoding, and idea generation will prove less complicated $[8,29,58]$. Moreover, TL creates an empowered working environment by instilling beliefs of creative self-efficacy, psychologically safe and intrinsically motivated work-settings to engaging employees in innovative tasks [4] more frequently. Existing studies provide the foundation for Hypothesis 5.

Hypothesis 5 (H5). Creative process engagement mediates the relationship between transformational leadership and sustainable innovative work behaviour.

\subsection{Research Framework}

A conceptual model (Figure 1) exhibits how CPE bridges intrinsic motivation with proactivity to innovative work behaviour via the full-fledged effects of TL. Unlike other studies which conceive innovative behaviour from a particular perspective, this study considers innovative behaviour from the integration of multiple contexts. Hence, the CPE stems not only from the tenets of the componential theory of creativity but also relates to individual and contextual factors [59]. We use proactive behaviour and intrinsic motivation at the individual level and TL at the group level. Thus, the conceptual model illustrates that sustainable IWB is the outcome of a process bringing both the individual and contextual factors together.

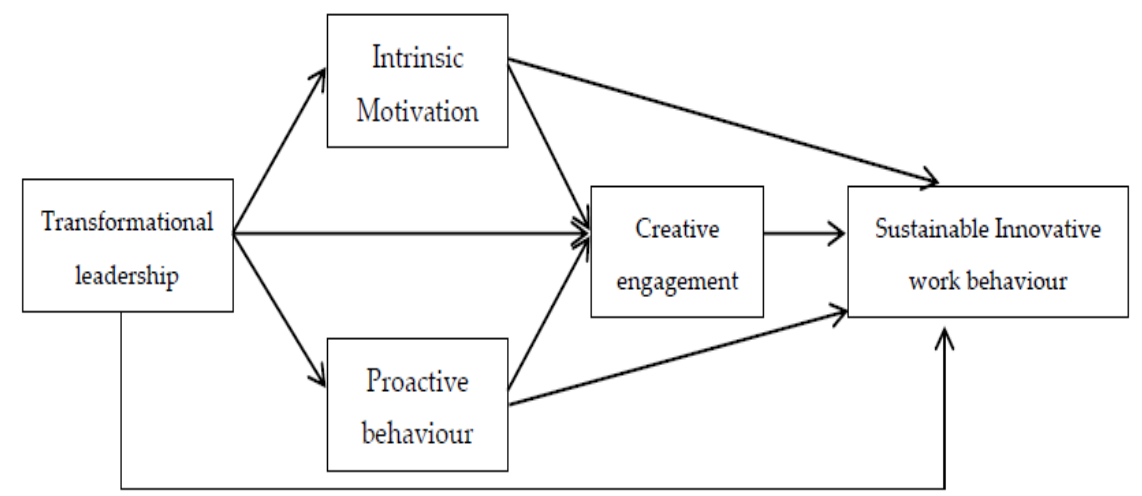

Figure 1. Conceptual model.

\section{Research Methods}

\subsection{Sample Design and Data Collection}

In a quantitative study, data were collected from large-scale readymade-garment factories located in the Chittagong Export Processing Zone (CEPZ) in Bangladesh, which employs a globally competent workforce. In line with Brislin's [60] suggestions, all survey instruments were translated and re-translated into the native language (Bangla) by a panel of language experts and researchers in management science. Five hundred questionnaires were sent to organisations via personal visits and email attachments, and 245 pairs of responses from leaders and their followers were received. Each pair comprises a head of department and his/her immediate subordinate to form a dyad. The head of the department filled in the responses about his/her subordinate's CPE, proactivity, and sustainable IWB, and the subordinate filled in the responses about his/her intrinsic motivation and the boss's TL. In the end, we used 236 pairs after deleting incomplete replies.

Table 1 displays the demographic profile of the respondents consisting of diversity in composition. The composition of gender was 31\% female and $69 \%$ male. The respondents represent those with a 
bachelor's (16\%) degree, graduate (18\%) degree, and a master's degree or diploma (66\%). Fifty-one percent of the respondents were between 25 to 35 years old and the rest (49\%) were over 35 years old. Their tenure profile revealed that $51 \%$ of them have 5 to 10 years' working experience whereas $49 \%$ of them have above 10 years of tenure experience. Over one-third $(41 \%)$ of the responses were received from the production department, followed by commercial $(27 \%)$, human resources $(15 \%)$, quality control $(10 \%)$, and other $(7 \%)$ departments.

Table 1. Demographic profile of the respondents $(n=236)$.

\begin{tabular}{|c|c|c|}
\hline Aspects & Frequency & Percentage \\
\hline \multicolumn{3}{|l|}{ Age } \\
\hline Above 18 & 18 & 8 \\
\hline Above 25 & 121 & 51 \\
\hline Above 35 & 83 & 35 \\
\hline Above 45 & 14 & 6 \\
\hline \multicolumn{3}{|l|}{ Education } \\
\hline Graduate & 37 & 16 \\
\hline Master & 156 & 66 \\
\hline Others & 43 & 18 \\
\hline \multicolumn{3}{|l|}{ Experience } \\
\hline Above 1 Years & 61 & 26 \\
\hline Above 5 Years & 120 & 51 \\
\hline Above 10 Years & 47 & 20 \\
\hline Above 15 Years & 8 & 3 \\
\hline \multicolumn{3}{|l|}{ Ownership } \\
\hline Local & 118 & 50 \\
\hline Foreign & 118 & 50 \\
\hline \multicolumn{3}{|l|}{ Gender } \\
\hline Male & 164 & 69 \\
\hline Female & 72 & 31 \\
\hline \multicolumn{3}{|l|}{ Department } \\
\hline Production & & \\
\hline Commercial & 63 & $\begin{array}{l}41 \\
27\end{array}$ \\
\hline Human & $\begin{array}{l}63 \\
36\end{array}$ & $\begin{array}{l}27 \\
15\end{array}$ \\
\hline Resources & 23 & 10 \\
\hline $\begin{array}{c}\text { Quality control } \\
\text { Others }\end{array}$ & 17 & 7 \\
\hline
\end{tabular}

\subsection{Common Method Bias}

The authors applied several techniques to prevent common method bias [61]. Harman's one-factor test of all variables was used to the obtain the common method bias problem, and the principal component analysis exhibited that not a single component explained more than $50 \%$ variance. We also tested the correlations matrix among the constructs recommended by Pavlou, et al. [62], which revealed that none of them exceed 0.90, as Harman's one-factor test has been criticised. The respondents were assured of confidentiality, which prompted them to provide accurate replies [63]. Lastly, we chose both report (self-report and others' report) surveys instead of self-reported data to avoid the 'halo effect' and social desirability bias [64]. Thus we were not concerned with method and response biases.

\subsection{Control Variables}

We considered employees' age, gender, education, tenure and department, and the ownership of the firm and modelled them as the control variable in this study. The control variables were age ( $1=18-24$ years old, $2=25-34$ years old, $3=35$ to 44 years old, and $5=$ over 44 years $)$, gender $(1=$ male, and $2=$ female $)$, education $(1=$ graduate, $2=$ master's, and $3=$ others $)$, tenure $(1=1-4$ years, $2=5-9$ years, $3=10-14$ years, and $4=$ more than 14 years $)$, department $(1=$ production, $2=$ commercial, 
$3=$ human resources, $4=$ quality control, and $5=$ others $)$, and ownership of the firm $(1=$ local firm, and 2 = international firm). Prior studies, for example Uddin, Mahmood and Fan [61], Zhang and Bartol [11], and Du, et al. [65], showed that demographic variables have major influences on employees' creative pursuit.

\subsection{Measurement Tools}

This study has adopted a total of five different measures from five different sources: sustainable innovative work behaviour from Zhang and Begley [66], creative process engagement from Zhang and Bartol [11], transformational leadership from Podsakoff, et al. [67], intrinsic motivation from Zhang and Bartol [11], and proactive behaviour from Parker, et al. [68]. A 5-point Likert scale was used to administer the survey and the respondents were asked to rate each statement on a 5-point Likert scale $(1=$ strongly agree $\ldots 5=$ strongly disagree). The measurement items are stated in Appendix A Table A1.

\section{Model Evaluation}

The authors used a list of analytical tools, such as MS Excel 2016, IBM SPSS 21, and SmartPLS2. We applied structural equation modelling (SEM) in this study because it is the second-generation regression analytical technique that analyses all results following the two-step process. First, it tests the measurement model using confirmatory factor analysis, and second, it estimates the structural model using path analysis and model fitness test $[69,70]$.

\subsection{Measurement Model}

At the measurement level, each item in a construct was tested to justify its suitability to include it for measuring the underlying construct. To measure the measurement items' suitability representing the construct, internal consistency, convergent validity, and discriminant validity have been used in SmartPLS-2 [71]. Both composite reliability and Cronbach's alpha $(\alpha)$ are used to predict internal consistency. Scales with $\alpha$-level from 0.80 and above are considered very good [72]. One item from the $\mathrm{CPE}$ (cpe1) measure is dropped because of its reduced loading. Since the composite reliability and $\alpha$ of all five constructs are estimated above the cut-off value $(0.885$ for composite reliability and 0.805 for $\alpha$ ) in Table 1, all measures are considered reliable [69,73]. In addition, Table 2 represents convergent validity, which presents average variance extracted (AVE). It shows that the AVE of each construct is above the minimum acceptable threshold limit of $0.50[69,73]$.

Table 2. Result for internal consistency and convergent validity.

\begin{tabular}{cccccc}
\hline Constructs & Sources & AVE & CR & CA & $\mathbf{R}^{\mathbf{2}}$ \\
\hline TL & Podsakoff, MacKenzie and Bommer [67] & 0.694 & 0.919 & 0.890 & NA \\
PB & Parker, Williams and Turner [68] & 0.689 & 0.930 & 0.910 & 0.256 \\
IM & Zhang and Bartol [11] & 0.682 & 0.865 & 0.766 & 0.255 \\
CPE & Zhang and Bartol [11] & 0.632 & 0.945 & 0.935 & 0.241 \\
SIWB & Zhang and Begley [66] & 0.732 & 0.942 & 0.927 & 0.474 \\
\hline
\end{tabular}

TL. Transformational leadership, PB. Proactive beahviour, IM. Intrinsic motivation, CPE. Creative process engagement, SIWB Sustainable innovative work behavior, AVE. Average variance extracted, CR. Composite reliability, CA. Cronbach's Alpha.

Moreover, discriminant validity analysis reports, in Table 3, that the square root of the AVE of each construct is higher than the construct's highest correlation with other constructs [69]. It supports the core tenet of discriminant validity that the correlation score between the same construct in their diagonal matrix is higher than their correlations with other constructs. Thus, there is no concern with the discriminant validity result. The result also highlighted that control variables are not significantly correlated with the latent variables. The displayed result showed that there is very little concern that a control variable will have any influence at all on endogenous variables. 
Table 3. Correlation matrix of discriminant validity.

\begin{tabular}{|c|c|c|c|c|c|c|c|c|c|c|c|c|c|}
\hline & Mean & SD & 1 & 2 & 3 & 4 & 5 & 6 & 7 & 8 & 9 & 10 & 11 \\
\hline $\begin{array}{c}\text { Control } \\
\text { variables }\end{array}$ & - & - & & & & & & & & & & & \\
\hline 1. Age & - & - & 1.00 & & & & & & & & & & \\
\hline 3. Tenure & - & - & $0.651 * *$ & $0.278 * *$ & 1.00 & & & & & & & & \\
\hline 4. Nature of firm & - & - & -0.06 & 0.03 & 0.02 & 1.00 & & & & & & & \\
\hline 5. Sex & - & - & $-0.286 * *$ & $-0.196 * *$ & $-0.187^{* *}$ & -0.04 & 1.00 & & & & & & \\
\hline 6. Departments & - & - & $0.208^{* *}$ & 0.00 & $0.251 * *$ & 0.01 & -0.10 & 1.00 & & & & & \\
\hline \multicolumn{14}{|l|}{ Latent variables } \\
\hline 7. TL & 2.05 & 0.628 & -0.06 & -0.06 & 0.00 & 0.03 & 0.07 & 0.06 & 0.833 & & & & \\
\hline 8. IM & 1.95 & 0.620 & -0.11 & -0.11 & -0.06 & 0.11 & 0.08 & 0.10 & $0.471^{* *}$ & 0.826 & & & \\
\hline 9. $\mathrm{PB}$ & 2.09 & 0.738 & -0.03 & -0.08 & 0.05 & 0.07 & -0.03 & 0.11 & $0.491 * *$ & $0.459 * *$ & 0.830 & & \\
\hline 10. CPE & 1.93 & 0.630 & -0.13 & -0.11 & -0.08 & 0.05 & 0.13 & 0.11 & $0.297^{* *}$ & $0.452 * *$ & $0.445^{* *}$ & 0.795 & \\
\hline 11. SIWB & 1.88 & 0.667 & -0.12 & -0.14 & -0.09 & 0.05 & $0.099 * *$ & 0.11 & $0.358^{* *}$ & 0.489 ** & $0.418^{* *}$ & $0.638^{* *}$ & 0.855 \\
\hline
\end{tabular}

Note: ${ }^{* *}$. Correlation is significant at the 0.01 level (2-tailed). SD. Standard deviation, TL. Transformational leadership, IM. Intrinsic motivation, PB. Proactive behaviour, CPE. Creative process engagement, and SIWB. Sustainable innovative work behaviour.

\subsection{Structural Model}

Instead, the authors adopted multiple assessment criteria to estimate the structural model-quality and fitness from various perspectives, rather than rely solely on the beta-coefficient $(\beta)$, coefficient of determination $\left(R^{2}\right)$, and multi-collinearity [74]. Whereas $\beta$ represents the strength of the relationship between exogenous and endogenous variables, $R^{2}$ predicts the overall power of the model explaining the dependent variable.

Figure 2 represents the bootstrapping results in a case of 5000 samples for finding t-statistics to test each hypothesised relationship and, lastly, reports their significance at different levels. The result shows that this model explains $25.5 \%$ of the variance in intrinsic motivation, $25.6 \%$ in proactive behaviour, $24.1 \%$ in CPE, and $47.4 \%$ in IWB. There are three different threshold levels, such as variable to the range of 0 to $0.13,0.13$ to 0.26 , and 0.26 and above represents not significant, tangential, and significant, respectively [75]. Therefore, all variables in this study are tangential and significant. Moreover, Hair Jr, et al. [76] posited that an $R^{2}$ above 0.20 is considered high in behavioural science. Since the minimum $R^{2}$ is 0.24 (above 0.20 for CPE), $R^{2}$ is not a major concern.

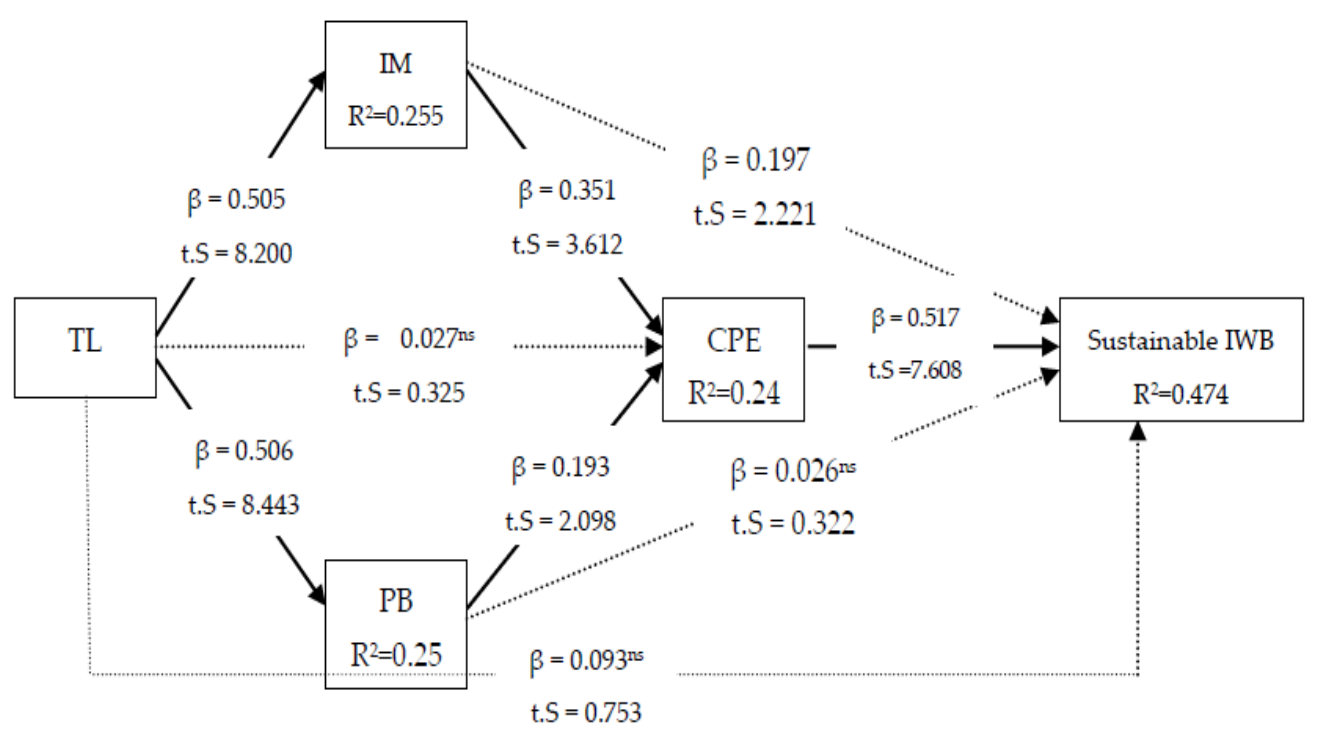

Figure 2. Path model along with their $\beta$ and t-Statistics (t.S); ns. Not significant: all paths except path with ns are significant at $p<0.02$. 
The authors also employed the model of the goodness of fit, in Equation (1), for the partial least square, as advocated by Tenenhaus, et al. [77], which equals the square root of the product of average communalities of all constructs and $R^{2}$ of all endogenous variables as follows:

$$
\begin{gathered}
\text { Goodness of Fit }(\mathrm{GoF})=\sqrt{\text { Average communality } \times \text { Average } R^{2}} \\
\text { GoF }=\sqrt{0.682 \times 0.307} \\
\text { GoF }=0.458
\end{gathered}
$$

Cohen [78] and Wetzels, et al. [79] mentioned 0.10, 0.25, and 0.36 for the goodness of fit to be small, medium, and large effect sizes, on the condition that the minimum threshold limit for communality be above 0.50 [80]. Since the estimated results of the goodness of fit and minimum communality are more significant than the baseline (for example, goodness of fit $=0.458$ and communality $=0.632$ ), this model's effect size is large [78-80]. Furthermore, multi-collinearity issues were verified because their existence posited vulnerable regression weights with larger standard errors [4]. Tested results, in Table 4, using a variance inflation factor reflected that multi-collinearity issues are not a serious concern since the highest variance inflation factor $(\mathrm{SIWB}=1.868)$ is below 3.00 .

Table 4. Collinearity assessment.

\begin{tabular}{cccccc}
\hline Construct & TL & PB & IM & CPE & SIWB \\
\hline Variance inflation factor & 1.476 & 1.410 & 1.495 & 1.840 & 1.868 \\
\hline Tolerance & 0.678 & 0.709 & 0.669 & 0.543 & 0.535 \\
\hline
\end{tabular}

TL. Transformational leadership, PB. Proactive behaviour, IM. Intrinsic motivation, CPE. Creative process engagement, SIWB. Sustainable innovative work behaviour.

\section{Findings}

\subsection{Hypothesis Testing}

The hypotheses above can be divided into two types: in terms of the direct effects of the independent variable on the dependent variable, and in terms of the effect of the mediating variables on the relationship between independent variables and dependent variables. Hence, our hypothesis testing results are reported as unmediated and mediated results.

\subsection{Mediation Effect}

The necessary condition of a mediation effect is to have a significant direct effect (such as $\mathrm{c}$ in Figure 3) of the independent variable on the dependent variable before adding a mediating variable [81-83]. Table 3 shows that all the independent variables have significant effects on dependent variables. Figure 3 demonstrates the mediated and unmediated relations in a structured model. Sufficient conditions for a mediation effect are, first, that the independent variable must affect the mediating variable significantly; secondly, both independent variable and mediating variable must also predict the dependent variable significantly; and lastly, the significant direct effect $\left(c^{\prime}\right)$ of the independent variable on the dependent variable must disappear (for full mediation) or reduce (for partial mediation) when the mediating variable is used in the previous unmediated relationship [81-83]. 


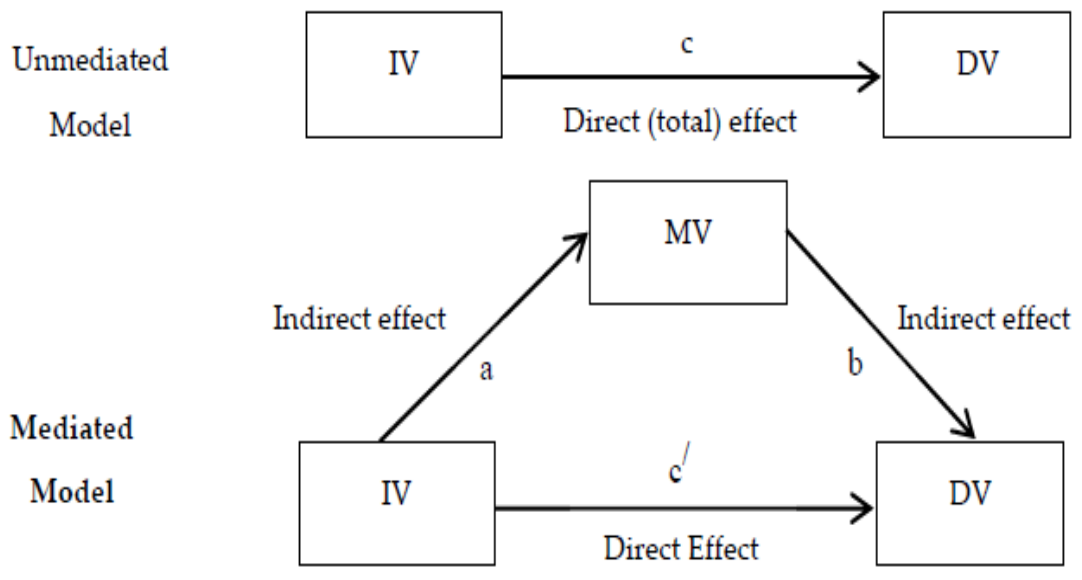

Figure 3. Total, direct, and indirect effects in unmediated and mediated models.

Table 5 shows that the unmediated relationship between CPE and sustainable IWB $(\beta=0.648$, $t=12.748, p<0.00)$, TL and CPE $(\beta=0.315, t=5.038, p<0.00)$, IM and sustainable IWB $(\beta=0.497$, $t=8.100, p<0.00)$, proactive behaviour and sustainable $\operatorname{IWB}(\beta=0.371, t=5.277, p<0.00)$, and TL and sustainable IWB $(\beta=0.369, t=5.503, p<0.00)$ are significant. Therefore, it can be claimed that all the predictor variables mentioned in Table 5 significantly influence their explained variables.

Table 5. Unmediated result.

\begin{tabular}{cccccc}
\hline Path Relationship & $\boldsymbol{\beta}$ & $\boldsymbol{R}^{\mathbf{2}}$ & T-Statistics & $\boldsymbol{p}$ Value & Decision \\
\hline $\mathrm{CPE} \longrightarrow \mathrm{SIWB}$ & 0.645 & 0.416 & 12.748 & 0.000 & Supported \\
\hline $\mathrm{TL} \longrightarrow \mathrm{CPE}$ & 0.315 & 0.100 & 5.038 & 0.000 & Supported \\
\hline $\mathrm{IM} \longrightarrow \mathrm{SIWB}$ & 0.497 & 0.247 & 8.100 & 0.000 & Supported \\
\hline $\mathrm{PB} \longrightarrow \mathrm{SIWB}$ & 0.371 & 0.138 & 5.277 & 0.000 & Supported \\
\hline $\mathrm{TL} \longrightarrow \mathrm{SIWB}$ & 0.369 & 0.136 & 5.503 & 0.000 & Supported \\
\hline
\end{tabular}

Table 6 reports the direct, indirect, and total effect of predictor variables on explained variables before and after using the mediating variables. We found (in Table 5) that the necessary condition exists for a mediating effect, since the direct effects of independent variables on dependent variables before adding the mediating variable is significant. Additionally, Figure 2 also reveals the $\beta \mathrm{s}$, t-statistics, and $R^{2}$ through the SEM. Table 6 demonstrates all the direct effects, except for intrinsic motivation, on sustainable IWB $(\beta=0.197, t=2.221, p<0.027)$ reported in Figure 2 and Table 6 , such that TL on CPE $(\beta=0.027, t=0.325, p<0.746)$, proactive behaviour on sustainable IWB $(\beta=0.026, t=0.322, p<0.747)$ and TL on sustainable IWB $(\beta=0.094, t=1.016, p<0.311)$ are insignificant after adding mediating variables. Examining the mediation effect of $\mathrm{CPE}$ on TL and sustainable IWB relations in $\mathrm{H} 5$, the results show that on the one hand, the indirect effect of TL on CPE $(\beta=0.027, t=0.325, p<0.746)$ becomes insignificant, and on the contrary, the direct effect has also been reported insignificant previously. Except for H5, the reported results in Table 6 and Figure 3 prove that all other mediating effects exist, fulfilling both necessary and sufficient conditions [81,82].

According to the mediation parameters given by Chou and Yeh [81], Hayes (2013) and Baron and Kenny [83], H1, H2, and H4 have a full mediation effect because direct paths (c) become insignificant after running the mediator variables. In $\mathrm{H} 3$, although the direct effect of proactive behaviour is still significant after adding the mediator variable (CPE), partial mediation is noticed because $\beta$ is significantly reduced from $\beta=0.497$ to $\beta=0.197$. In addition, to understand the extent of the mediation effect, the variance accounted for (VAF) is calculated [69]. Likewise, full mediation is noticed in $\mathrm{H} 1$ and $\mathrm{H} 2$ where VAF for intrinsic motivation and proactive behaviour are 0.87 and 0.78 (close to 0.80 ) respectively. The partial mediation and the full mediation of CPE are estimated based on 
the relationships between intrinsic motivation and sustainable IWB, and proactive behaviour and sustainable IWB in $\mathrm{H} 3$ and $\mathrm{H} 4$ with their VAF scores, such as 0.48 (VAF < 0.80) and 0.79 (VAF close to 0.80 ) respectively [69]. The result is also examined by Sobel [84] to estimate the significance of the indirect effect. The estimated results of the mediating variables using the method developed by Soper [85] are found to be significant at $p<0.04$, except for the last hypothesis, H5. Therefore, the results represented in Table 6 and Figure 2 justify the authors' claims in their hypotheses.

Table 6. Mediated result.

\begin{tabular}{|c|c|c|c|c|c|c|c|c|c|}
\hline & Path & $\beta$ & $\begin{array}{l}\text { Standard } \\
\text { Error }\end{array}$ & $t$ & $p$ & $\begin{array}{l}\text { Indirect } \\
\text { Effect * }\end{array}$ & $\begin{array}{c}\text { Total } \\
\text { Effect ** }\end{array}$ & VAF & Sobel Test \\
\hline \multirow{4}{*}{ H1 } & $\mathrm{TL} \longrightarrow \mathrm{CPE}(\mathrm{c})$ & 0.315 & 0.062 & 5.038 & 0.000 & \multirow{4}{*}{0.177} & \multirow{4}{*}{0.204} & \multirow{4}{*}{$0.87^{\mathrm{FM}}$} & \multirow{4}{*}{$\begin{aligned} \mathrm{Z} & =3.307 \\
p & <0.00\end{aligned}$} \\
\hline & $\mathrm{TL} \longrightarrow \mathrm{IM}(\mathrm{a})$ & 0.505 & 0.062 & 8.200 & 0.000 & & & & \\
\hline & $\mathrm{IM} \longrightarrow \mathrm{CPE}(\mathrm{b})$ & 0.351 & 0.097 & 3.612 & 0.000 & & & & \\
\hline & $\mathrm{TL} \rightarrow \mathrm{CPE}\left(\mathrm{c}^{\prime}\right)$ & 0.027 & 0.083 & 0.325 & $0.746^{\mathrm{ns}}$ & & & & \\
\hline \multirow{4}{*}{ H2 } & $\mathrm{TL} \longrightarrow \mathrm{CPE}$ (c) & 0.315 & 0.0618 & 5.038 & 0.000 & \multirow{4}{*}{0.098} & \multirow{4}{*}{0.125} & \multirow{4}{*}{$0.78^{\mathrm{FM}}$} & \multirow{4}{*}{$\begin{array}{c}\mathrm{Z}=2.036 \\
p<0.04\end{array}$} \\
\hline & $\mathrm{TL} \longrightarrow \mathrm{PB}(\mathrm{a})$ & 0.506 & 0.060 & 8.443 & 0.000 & & & & \\
\hline & $\mathrm{PB} \longrightarrow \mathrm{CPE}(\mathrm{b})$ & 0.193 & 0.092 & 2.098 & 0.037 & & & & \\
\hline & $\mathrm{TL} \longrightarrow \mathrm{CPE}\left(\mathrm{c}^{\prime}\right)$ & 0.027 & 0.083 & 0.325 & $0.746^{\mathrm{ns}}$ & & & & \\
\hline \multirow{4}{*}{ H3 } & $\mathrm{IM} \longrightarrow \mathrm{SIWB}$ (c) & 0.497 & 0.060 & 8.100 & 0.000 & \multirow{4}{*}{0.181} & \multirow{4}{*}{0.378} & \multirow{4}{*}{$0.48^{\mathrm{PM}}$} & \multirow{4}{*}{$\begin{aligned} \mathrm{Z} & =3.267 \\
p & <0.00\end{aligned}$} \\
\hline & $\mathrm{IM} \longrightarrow \mathrm{CPE}(\mathrm{b})$ & 0.351 & 0.097 & 3.612 & 0.000 & & & & \\
\hline & $\mathrm{CPE} \longrightarrow$ SIWB (b) & 0.517 & 0.068 & 7.608 & 0.000 & & & & \\
\hline & $\mathrm{IM} \longrightarrow \mathrm{SIWB}\left(\mathrm{c}^{\prime}\right)$ & 0.197 & 0.089 & 2.221 & 0.027 & & & & \\
\hline \multirow{4}{*}{ H4 } & $\mathrm{PB} \longrightarrow \mathrm{SIWB}(\mathrm{c})$ & 0.371 & 0.0696 & 5.277 & 0.000 & \multirow{4}{*}{0.100} & \multirow{4}{*}{0.126} & \multirow{4}{*}{$0.79 \mathrm{FM}$} & \multirow{4}{*}{$\begin{array}{c}\mathrm{Z}=2.0221 \\
p<0.04\end{array}$} \\
\hline & $\mathrm{PB} \longrightarrow \mathrm{CPE}(\mathrm{a})$ & 0.193 & 0.092 & 2.098 & 0.037 & & & & \\
\hline & $\mathrm{CPE} \longrightarrow$ SIWB (b) & 0.517 & 0.068 & 7.608 & 0.000 & & & & \\
\hline & $\mathrm{PB} \longrightarrow \mathrm{SIWB}\left(\mathrm{c}^{\prime}\right)$ & 0.026 & 0.081 & 0.322 & $0.747^{\mathrm{ns}}$ & & & & \\
\hline \multirow{4}{*}{ H5 } & $\mathrm{TL} \longrightarrow \mathrm{SIWB}(\mathrm{c})$ & 0.369 & 0.0655 & 5.503 & 0.000 & \multirow{4}{*}{ NA } & \multirow{4}{*}{ NA } & \multirow{4}{*}{ NA } & \multirow{4}{*}{ NA } \\
\hline & $\mathrm{TL} \longrightarrow \mathrm{CPE}$ (a) & 0.027 & 0.083 & 0.325 & $0.746^{\mathrm{ns}}$ & & & & \\
\hline & $\mathrm{CPE} \longrightarrow \mathrm{SIWB}(\mathrm{b})$ & 0.517 & 0.068 & 7.608 & 0.000 & & & & \\
\hline & $\mathrm{TL} \longrightarrow \mathrm{SIWB}\left(\mathrm{c}^{\prime}\right)$ & 0.094 & 0.093 & 1.016 & $0.311^{\mathrm{ns}}$ & & & & \\
\hline
\end{tabular}

Notes: VAF. Variance accounted for, ${ }^{\text {ns }}$ Not significant; ${ }^{*}$. Indirect effect $=a$ times $b$; ${ }^{* *}$. Total effect $=c^{\prime}+$ Indirect effect, VAF = Indirect effect/total effect, ${ }^{\mathrm{FM}}$ Full mediation, ${ }^{\mathrm{PM}}$ Partial mediation, ${ }^{\mathrm{NM}}$ No mediation.

\section{Discussion}

Zhang and Bartol [11] reveal that leadership morale and supervisory support empower its employees psychologically. This psychological empowerment tends to foster intrinsically motivated employees to engage in the creative process. Gumusluoglu and Ilsev [1] show partial mediation of intrinsic motivation between TL and creativity, but it was not statistically significant. However, Shin and Zhou [40] also notice the partial mediation effect on TL and creativity. The present study supported previous studies on the mediating effect (H1) of intrinsic motivation on TL-CPE. Den Hartog and Belschak [86] and Deluga [87] highlight the positive influence of TL and charismatic leadership on the proactivity of employees by underlining their effect and commitment to them. The existing literature shows that the proactivity of employees leads them in creative and innovative pursuits [44,51]. The present study supports the hypothesised relationship $(\mathrm{H} 2)$ on the mediating role of proactive behaviour between the TL and CPE relationship.

The hypothesis on the mediation (H3) of CPE on intrinsic motivation-sustainable IWB is supported by Kahn [36], Zhang and Bartol [11], and Gilson and Shalley [9]. Zhang and Bartol [11] mention that intrinsically motivated employees devote their attention to the problem areas in an organisation, and Kahn [36] contends that CPE requires personal-self engagement in work roles physically, cognitively, and behaviourally. This creative process is the primary input to the innovative outcome [9]; Parker [88], Crant [49] and Crant and Bateman [89]. Parker (1998) reports that proactive employees seek new information and better ways (like the $\mathrm{CPE}$ ) to use their active participation to improve the work process.

The extant literature also shows the significant impact of CPEs on sustainable IWB $[8,10,11,52]$. Research reveals that there is direct empirical support for the mediation effect of CPE on proactive behaviour and sustainable IWB relationships. However, synchronising the findings of the previous 
citations, it can be concluded that previous findings support the result (H4) of the mediation effect of $\mathrm{CPE}$ on the relationship between proactive behaviour and sustainable IWB.

In contrast to our previous hypotheses ( $\mathrm{H} 1, \mathrm{H} 2, \mathrm{H} 3$, and $\mathrm{H} 4), \mathrm{H} 5$ demonstrates that $\mathrm{CPE}$ does not mediate the relationship between TL and sustainable IWB. Although the direct effect before running the mediator (CPE) is significant $(\beta=0.369, t=5.503, p<0.00)$, the direct effect of TL on sustainable $\operatorname{IWB}(\beta=0.094, t=1.016, p<0.311)$, and the indirect effect of TL on CPE $(\beta=0.027, t=0.325, p<0.746)$, are found insignificant after adding the mediator variable. It seems that TL impacts sustainable IWB through the mediation of proactive behaviour, intrinsic motivation, and CPE rather than through the mediation of CPE alone. This illustrates that TL influences employees' intrinsic motivation and proactive behaviour towards CPE, and eventually that CPE impacts sustainable IWB. Hence, the direct mediation of CPE is not supported.

Unlike previous studies carried out in the Western context, the present study offers new evidence to advance empirical findings in a developing country's context by showing that sustainable IWB-directed CPE is undoubtedly possible in Bangladesh through the stimulation of employees' intrinsic motivation and proactive behaviour [4]. The use of TL, a value-driven leadership, in a developing country's context boosts the employees' intrinsic motivation and proactive behaviour towards CPE and sustainable IWB. In line with the tenets of individual creative action theory [17], the present findings also reiterated that $\mathrm{CPE}$ and sustainable IWB are possible in Bangladesh, a developing country, since it undergoes not only the challenges of withholding the continuous progress supported by the autonomous motivation of capable employees but also has a dynamic leadership (TL) in readymade-garments manufacturing to lead the progress.

\section{Contributions}

This study sets out to discover the predictors of the sustainable IWB of executives in the EPZ area. The existing literature explains that innovation does not solely take place at a single level, but it spans those levels $[90,91]$. This study considers that sustainable IWB is the outcome of many actors across levels, such as the group level (TL) and the individual level (proactive behaviour, intrinsic motivation, $\mathrm{CPE}$, and IWB). Contrary to the findings of Jaiswal and Dhar [6], Qu, Janssen and Shi [53], and Mittal and Dhar [26], and in compliance with the propositions of Thomas [47], Zhang and Bartol [11], Zhang and Bartol [10], Shipman [56], and Du, Zhang and Chen [65], this empirical study focuses on innovation as a creative outcome of the creative process engagement. Therefore, employee engagement in the creative process leads to creative outcomes in an enterprise.

Although a growing body of studies has proliferated over the past few decades, the process part of innovation, such as creative engagement, has received little or no attention [47]. Following an understanding of the model of individual creative action, as opposed to the tenets of the componential theory of creativity, this study builds on the notion that innovation, being perceived to be both process and outcome, is the result of contextual supports from TL. This study partially negates the core of the componential theory of creativity by declining the absolute surrender of innovative behaviour to creative genius. However, the model of individual creative action extends previous beliefs to include the fact that $\mathrm{CPE}$ and IWB are the functions of individual creative skill, expertise, motivation, and favourable contingencies via TL [92-94].

This study proposes a unique conceptual model that integrates five different measures along with generally acclaimed theories, TL, the componential theory of creativity, and the model of individual creative action. It reaches the conclusion that the model of individual creative action is the most effective theory to engage employees physically, behaviourally, and emotionally in the creative process to reap innovative outcomes over a long period of time. Although studies have shown that leadership is very important for IWB $[11,56]$, the impact of TL on CPE and IWB has been surprisingly neglected.

This study also considers proactive behaviour as a significant predictor of $\mathrm{CPE}$ and sustainable IWB, as suggested by Zhang and Bartol [11] in their studies. The result reveals that proactive behaviour contributes to IWB by influencing CPE among employees. Unlike the study by Henker, Sonnentag 
and Unger [8], this study collects data from multiple sources. Therefore, a generalised result is achieved. Furthermore, most of the studies and the models on creativity and innovation cited here were investigated in developed countries, and therefore Zhang and Bartol [11] suggest that empirical studies in other contexts will re-establish the generalisability of the theories. This study, conducted in the Bangladesh context, not only contributes to alleviating the deficiency in the literature on innovation and creativity in developing countries but also supports the generalisability of previous results.

\subsection{Managerial Implications}

The study has several implications for practising managers while demonstrating their supervisory roles. First, the supervisors or managers should display their TL traits to stimulate their subordinates to participate in the creative process and maintain innovative behaviour. Notably, leaders should be very vigilant when using other leadership styles because executives' intrinsic motivation and proactive behaviours, which are essential for $\mathrm{CPE}$ and IWB, as driven by TL, might be significantly reduced. Second, this study contends that managers or supervisors are expected to devote significant time to investigating how they can involve and engage their executives in CPE and, therefore, continue towards IWB by shaping an employee-centric climate. Third, TL must create an interactive atmosphere across levels and among seniors and juniors because interaction between leaders and followers eases their psychological worries related to leaders giving up on them during their failures and problems, which plays a significant role in boosting their intrinsic motivation and proactivity to engage in the creative process and in sustainable innovative work behaviour. Fourth, inclusive involvement of TL provides a psychological safety net by shedding individualised considerations and, as a result, provokes employees to become involved in CPE and sustainable IWB. When relieved from psychological intimidation and social disintegration, employees, as a consequence, will build up a broader repertoire of new ideas and participate in potentially risky activities continuously to maintain innovativeness, as they assume no deprivation of a leader's support if needed [95-97]. Lastly, practising managers are also needed, not only to hire talent but also to display their persuasive passion, flexibility, and various skills to instil belief and value in their immediate subordinates. Such a persuasive and value-based leadership style will have an impact on ownership of tasks and organisation on employees, leading them to reap creative outcomes from their engagement in the creative process.

\subsection{Limitations and Future Research}

The present study is also subject to certain restrictions which could be explored by future researchers. First, this study used cross-sectional data, which limits causality [8]. In addition, encouraging the employee toward IWB through CPE by influencing intrinsic motivation and proactive behaviour requires time. To ensure causality, longitudinal data from multiple organisations would be instrumental. Second, the study uses informants' responses from large-scale organisations from the EPZ area and extends the literature positing contradictory findings on the impact of organisational size on innovation pursuit. Vaccaro, et al. [98] report that leadership influence on employees tends to decline with an increase in organisation size due to the complexity of managing extensive management. Therefore, this study suggests that future researchers collect data from both large organisations and SMEs to examine the effect of organisational size on those previously tested hypotheses. Third, the study applies the model of individual creative action to examine the predictors of CPE and sustainable IWB. Innovation or creativity are multi-faceted processes, and CPE requires both employees and employers to engage in the process creatively. However, the study only considers individual and group levels, while organisational and environmental levels are overlooked. Lastly, the study is conducted in Bangladesh, an Asian hierarchical society that, as a culture, believes in avoiding uncertainty; thus, individuals are less likely to nurture creativity and innovation or to take risks [99]. Uncertainty avoidance shows a marked difference between those who are less creative and innovative and those who are more so. Thus, we recommend that future researchers detect the moderating effect of national culture, particularly uncertainty avoidance. 


\section{Conclusions}

This study attempts to understand how transformational leaders drive individuals' intrinsic motivation and proactivity towards creative process engagement and sustainable IWB. Drawing on an empirical study and theoretical lenses, the tested model describes how employees and their leaders are intertwined in the creative process and sustainable IWB in a developing country context. The study shows that intrinsic motivation and proactive behaviour fully mediate the relationship between CPE and TL. It also connects TL and IWB through the mediation of CPE. The reported results advance the understanding that TL is nonetheless directly connected to CPE and sustainable IWB and that transformational leaders' connection to employees' sustainable IWB disappears whenever intrinsic motivation, proactive behaviour, and CPE are employed as mediators. Henceforth, we suggest that future researchers and practitioners emphasise TL to navigate followers' intrinsic motivation and proactive behaviour in order to involve and engage them in the creative process leading to IWB.

Author Contributions: Conceptualization, L.Y., M.A.U. and A.K.D.; methodology, M.A.U., A.K.D. and M.M.; software, M.A.U. and A.K.D.; validation, L.Y., A.K.D. and S.M.S.; formal analysis, M.A.U.; investigation, M.A.U., A.K.D. and S.M.S.; resources, L.Y., A.K.D., M.M., and S.M.S.; data curation, A.K.D. and S.M.S.; writing-original draft preparation, M.A.U.; writing-review and editing, M.A.U., A.K.D., M.M. and S.M.S.; visualization, L.Y. and M.M.; supervision, L.Y. and M.M.; project administration, M.A.U. and A.K.D.; funding acquisition, L.Y., A.K.D., M.M. and S.M.S.

Funding: This research was supported by Humanities and Social Science Research Planning Foundation of Ministry of Education of China, grant number 18YJA630059.

Conflicts of Interest: The authors declare no conflict of interest.

\section{Appendix A}

Table A1. Survey questionnaire.

\begin{tabular}{|c|c|}
\hline Constructs & Measure Items \\
\hline $\mathrm{TL}$ & $\begin{array}{l}\text { The firm's management is always on the lookout for new opportunities for the organization. } \\
\text { The firm's management has a clear view of its final aims. } \\
\text { The firm's management succeeds in motivating the rest of the company. } \\
\text { The firm's management always acts as the organization's leading force. } \\
\text { The organization has leaders who are capable of motivating and guiding their colleagues on the job. }\end{array}$ \\
\hline $\begin{array}{l}\text { Proactive } \\
\text { Behaviour }\end{array}$ & $\begin{array}{l}\text { Employee implements ideas for improvements oneself. } \\
\text { Employee suggests ideas for improvements to colleagues. } \\
\text { Employee suggests ideas for improvements to manager, supervisor, or others. } \\
\text { Employee tries to figure out why reject levels are increasing. } \\
\text { Employee makes suggestions to relevant people as to why reject levels are high. } \\
\text { Employee informs the supplier about the problem. }\end{array}$ \\
\hline $\begin{array}{c}\text { Intrinsic } \\
\text { Motivation }\end{array}$ & $\begin{array}{l}\text { I enjoy finding solutions to complex problems. } \\
\text { I enjoy creating new procedures for work tasks. } \\
\text { I enjoy improving existing processes or products. }\end{array}$ \\
\hline $\mathrm{CPE}$ & $\begin{array}{l}\text { Employee thinks about the problem from multiple perspectives. } \\
\text { Employee decomposes a difficult problem/assignment into parts to obtain a greater understanding. } \\
\text { Employee consults a wide variety of information. } \\
\text { Employee searches for information from multiple sources (e.g., personal memories, others' experience, } \\
\text { documentation, the Internet, etc.). } \\
\text { Employee retains large amounts of detailed information in my area of expertise for future use. } \\
\text { Employee considers diverse sources of information in generating new ideas. } \\
\text { Employee looks for connections with solutions used in seeming diverse areas. } \\
\text { Employee generates a significant number of alternatives to the same problem before I choose the } \\
\text { final solution. } \\
\text { Employee tries to devise potential solutions that move away from established ways of doing things. } \\
\text { Employee spends considerable time shifting through information that helps to generate new ideas. }\end{array}$ \\
\hline SIWB & $\begin{array}{l}\text { Employee searches out new technologies, processes, techniques and product ideasEmployee generates } \\
\text { creative ideas. } \\
\text { Employee promotes and champions ideas to others. } \\
\text { Employee investigates and secure funds needed to implement new ideas. } \\
\text { Employee develops adequate plans and schedules for the implementation of new ideas. } \\
\text { Employee is innovative. }\end{array}$ \\
\hline
\end{tabular}




\section{References}

1. Gumusluoglu, L.; Ilsev, A. Transformational leadership, creativity, and organizational innovation. J. Bus. Res. 2009, 62, 461-473. [CrossRef]

2. Tsai, C.-F.; Yen, Y.-F. Moderating effect of employee perception of responsible downsizing on job satisfaction and innovation commitment. Int. J. Hum. Res. Manag. 2018, 1-25. [CrossRef]

3. Shih, H.-A.; Susanto, E. Perceived identifiability, shared responsibility and innovative work behavior. Int. J. Hum. Res. Manag. 2017, 28, 3109-3127. [CrossRef]

4. Mahmood, M.; Uddin, M.A.; Luo, F. Influence of Transformational Leadership on Employees' Creative Process Engagement: A Multi-Level Analysis. Manag. Decis. 2019, 57,741-764. [CrossRef]

5. Wang, X.-H.; Kim, T.-Y.; Lee, D.-R. Cognitive diversity and team creativity: Effects of team intrinsic motivation and transformational leadership. J. Bus. Res. 2016, 69, 3231-3239. [CrossRef]

6. Jaiswal, N.K.; Dhar, R.L. Transformational leadership, innovation climate, creative self-efficacy and employee creativity: A multilevel study. Int. J. Hosp. Manag. 2015, 51, 30-41. [CrossRef]

7. Gomes, C.; Curral, L.; Caetano, A. The mediating effect of work engagement on the relationship between self-leadership and individual innovation. Int. J. Innov. Manag. 2015, 19, 1550009. [CrossRef]

8. Henker, N.; Sonnentag, S.; Unger, D. Transformational leadership and employee creativity: The mediating role of promotion focus and creative process engagement. J. Bus. Psychol. 2015, 30, 235-247. [CrossRef]

9. Gilson, L.L.; Shalley, C.E. A Little Creativity Goes a Long Way: An Examination of Teams' Engagement in Creative Processes. J. Manag. 2004, 30, 453-470. [CrossRef]

10. Zhang, X.; Bartol, K.M. The influence of creative process engagement on employee creative performance and overall job performance: A curvilinear assessment. J. Appl. Psychol. 2010, 95, 862-873. [CrossRef]

11. Zhang, X.; Bartol, K.M. Linking empowering leadership and employee creativity: The influence of psychological empowerment, intrinsic motivation, and creative process engagement. Acad. Manag. J. 2010, 53, 107-128. [CrossRef]

12. Zheng, J.; Wu, G.; Xie, H. Impacts of Leadership on Project-Based Organizational Innovation Performance: The Mediator of Knowledge Sharing and Moderator of Social Capital. Sustainability 2017, 9, 1893. [CrossRef]

13. Si, S.; Wei, F. Transformational and transactional leaderships, empowerment climate, and innovation performance: A multilevel analysis in the Chinese context. Eur. J. Work Organiz. Psychol. 2012, 21, 299-320. [CrossRef]

14. Amabile, T.M. (Ed.) A Model of Creativity and Innovation in Organizations; JAI Press: Greenwich, CT, USA, 1988; Volume 10, pp. 123-167.

15. Amabile, T.M. Creativity and innovation in organizations. Harvard Bus. Rev. 1996, 5, 239-396.

16. Amabile, T.M. How to kill creativity. Harvard Bus. Rev. 1998, 87, 77-87.

17. Ford, C.M. A theory of individual creative action in multiple social domains. Acad. Manag. Rev. 1996, 21, 1112-1142. [CrossRef]

18. McMahon, S.R.; Ford, C.M. Heuristic Transfer in the Relationship Between Leadership and Employee Creativity. J. Leadersh. Organiz. Stud. 2012, 20, 69-83. [CrossRef]

19. Puente-Diaz, R. Creative self-efficacy: An exploration of its antecedents, consequences, and applied implications. J. Psychol. 2016, 150, 175-195. [CrossRef] [PubMed]

20. Minai, M.H.; Singh, S.; Varma, A. Leading for innovation. In Human Capital and Innovation; Springer: Berlin/Heidelberg, Germany, 2017; pp. 39-72.

21. Denti, L.; Hemlin, S. Leadership and innovation in organizations: A systematic review of factors that mediate or moderate the relationship. Int. J. Innov. Manag. 2012, 16, 1240007. [CrossRef]

22. Uddin, M.A.; Rahman, M.S.; Howlader, M.H.R. Empirical study on transformational leadership behavior, job performance, deviant workplace behavior and gender: Evidence from a study in bangladesh. Eur. J. Manag. Stud. 2017, 22, 77-97.

23. Howladar, M.H.R.; Rahman, M.S.; Uddin, M.A. Deviant Workplace Behavior and Job Performance: The Moderating Effect of Transformational Leadership. Iran. J. Manag. Stud. 2018, 11, 147-183. [CrossRef]

24. Fan, L.; Uddin, M.A.; Das, A.K. Empirical study on the antecedents of predicting organizational innovation of the small and medium enterprises in Bangladesh. J. Innov. Sustain. 2017, 8, 142-150. [CrossRef]

25. Uddin, M.A.; Fan, L.; Das, A.K. A study of the impact of transformational leadership, organizational learning, and knowledge management on organizational innovation. Manag. Dyn. 2017, 16, 42-54. 
26. Mittal, S.; Dhar, R.L. Transformational leadership and employee creativity: mediating role of creative self-efficacy and moderating role of knowledge sharing. Manag. Decis. 2015, 53, 894-910. [CrossRef]

27. Bai, Y.; Lin, L.; Li, P.P. How to enable employee creativity in a team context: A cross-level mediating process of transformational leadership. J. Bus. Res. 2016, 69, 3240-3250. [CrossRef]

28. Azim, M.T.; Luo, F.; Uddin, M.A.; Jilani, M.M.A.K.; Begum, S. Linking transformational leadership with employees' engagement in the creative process. Manag. Res. Rev. 2019. [CrossRef]

29. Uddin, M.A.; Fan, L.; Yang, X. The influence of transformational leadership on creative process engagement: Intrinsic motivation as a mediator. J. Wuhan Univ. Technol. Social Sci. Ed. 2018, 31, 78-83. [CrossRef]

30. Tan, C.-S.; Lau, X.-S.; Lee, L.-K. The mediating role of creative process engagement in the relationship between shyness and self-rated creativity. J. Creat. Behav. 2018. [CrossRef]

31. Gupta, V.; Singh, S.; Bhattacharya, A. The relationships between leadership, work engagement and employee innovative performance: Empirical evidence from the Indian R\&D context. Int. J. Innov. Manag. 2017, 21, 1750055. [CrossRef]

32. Podsakoff, P.M.; MacKenzie, S.B.; Lee, J.-Y.; Podsakoff, N.P. Common method biases in behavioral research: A critical review of the literature and recommended remedies. J. Appl. Psychol. 2003, 88, 879-903. [CrossRef]

33. Burns, J.M. Leadership; Harper \& Row: New York, NY, USA, 1978.

34. Bass, B.M. Leadership and Performance Beyond Expectations; The Free Press: New York, NY, USA, 1985.

35. Stoffers, J.M.; Van der Heijden, B.I.; Jacobs, E.A. Employability and innovative work behaviour in small and medium-sized enterprises. Int. J. Hum. Res. Manag. 2018, 1-28. [CrossRef]

36. Kahn, W.A. Psychological conditions of personal engagement and disengagement at work. Acad. Manag. J. 1990, 33, 692-724. [CrossRef]

37. Dewett, T. Linking intrinsic motivation, risk taking, and employee creativity in an R\&D environment. $R D$ Manag. 2007, 37, 197-208. [CrossRef]

38. Deci, E.L. Intrinsic motivation, extrinsic reinforcement, and inequity. J. Pers. Social Psychol. 1972, 22, 113-120. [CrossRef]

39. Oldham, G.R.; Cummings, A. Employee creativity: Personal and contextual factors at work. Acad. Manag. J. 1996, 39, 607-634. [CrossRef]

40. Shin, S.J.; Zhou, J. Transformational leadership, conservation, and creativity: Evidence from Korea. Acad. Manag. J. 2003, 46, 703-714. [CrossRef]

41. Belschak, F.D.; Hartog, D.N. Pro-self, prosocial, and pro-organizational foci of proactive behaviour: Differential antecedents and consequences. J. Occup. Organ. Psychol. 2010, 83, 475-498. [CrossRef]

42. Zhang, Z.; Wang, M.; Shi, J. Leader-follower congruence in proactive personality and work outcomes: The Mediating role of leader-member exchange. Acad. Manag. J. 2012, 55, 111-130. [CrossRef]

43. Liu, B.-C.; Shi, M.-H. Job insecurity, work-related stress and employee creativity: Proactive personality and team climate for innovation as moderators. In Proceedings of the International Conference on Management Science and Management Innovation (MSMI), Changsha, China, 14-15 June 2014.

44. Kim, T.-Y.; Hon, A.H.Y.; Lee, D.-R. Proactive personality and employee creativity: The Effects of job creativity requirement and supervisor support for creativity. Creat. Res. J. 2010, 22, 37-45. [CrossRef]

45. Amabile, T.M.; Conti, R.; Coon, H.; Lazenby, J.; Herron, M. Assessing the work environment for creativity. Acad. Manag. J. 1996, 39, 1154-1184. [CrossRef]

46. Ryan, R.M.; Deci, E.L. Self-determination theory and the facilitation of intrinsic motivation, social development, and well-being. Am. Psychol. 2000, 55, 68-78. [CrossRef]

47. Thomas, K.W. Intrinsic Motivation at Work: What Really Drives Employee Engagement; Berrett-Koehler Publishers: Oakland, CA, USA, 2009.

48. Liguori, E.W.; McLarty, B.D.; Muldoon, J. The moderating effect of perceived job characteristics on the proactive personality-organizational citizenship behavior relationship. Leadersh. Organ. Dev. J. 2012, 34, 724-740. [CrossRef]

49. Crant, J.M. Proactive Behavior in Organizations. J. Manag. 2000, 26, 435-462. [CrossRef]

50. Kim, T.-Y.; Hon, A.H.Y.; Crant, J.M. Proactive Personality, Employee Creativity, and Newcomer Outcomes: A Longitudinal Study. J. Bus. Psychol. 2009, 24, 93-103. [CrossRef]

51. Unsworth, K.; Parker, S.K. Promoting a proactive and innovative workforce for the new workplace. In The New Work-Place: A Guide to the Human Impact of Modern Working Practices; Holman, D., Wall, T.D., Clegg, C.W., Sparrow, P., Howard, A., Eds.; John Wiley \& Sons: Oakland, CA, USA, 2003. 
52. Gong, Y.; Cheung, S.-Y.; Wang, M.; Huang, J.-C. Unfolding the Proactive Process for Creativity. J. Manag. 2012, 38, 1611-1633. [CrossRef]

53. Qu, R.; Janssen, O.; Shi, K. Transformational leadership and follower creativity: The mediating role of follower relational identification and the moderating role of leader creativity expectations. Leadersh. Q. 2015, 26, 286-299. [CrossRef]

54. Afsar, B.; Badir, Y.F.; Saeed, B.B.; Hafeez, S. Transformational and transactional leadership and employee's entrepreneurial behavior in knowledge-intensive industries. Int. J. Hum. Res. Manag. 2016, 28, 307-332. [CrossRef]

55. Zhang, Y.; Zheng, J.; Darko, A. How Does Transformational Leadership Promote Innovation in Construction? The Mediating Role of Innovation Climate and the Multilevel Moderation Role of Project Requirements. Sustainability 2018, 10, 1506. [CrossRef]

56. Shipman, A.S. Leading for Creativity: Competing Leader Influence Tactics on Creative Engagement; University of Oklahoma: Norman, OK, USA, 2011.

57. Saeed, B.B.; Afsar, B.; Cheema, S.; Javed, F. Leader-member exchange and innovative work behavior: The role of creative process engagement, core self-evaluation, and domain knowledge. Eur. J. Innov. Manag. 2019, 22, 105-124. [CrossRef]

58. Hoch, J.E.; Bommer, W.H.; Dulebohn, J.H.; Wu, D. Do Ethical, Authentic, and Servant Leadership Explain Variance Above and Beyond Transformational Leadership? A Meta-Analysis. J. Manag. 2018, 44, 501-529. [CrossRef]

59. Choi, Y.S.; Lim, U. Contextual Factors Affecting the Innovation Performance of Manufacturing SMEs in Korea: A Structural Equation Modeling Approach. Sustainability 2017, 9, 1193. [CrossRef]

60. Brislin, R.W. Back-translation for cross-cultural research. J. Cross Cult. Psychol. 1970, 1, 185-216. [CrossRef]

61. Uddin, M.A.; Mahmood, M.; Fan, L. Why Individual Employee Engagement Matters for Team Performance? Mediating Effects of Employee Commitment and Organizational Citizenship Behaviour. Team Perform. Manag. Int. J. 2019, 25, 47-68. [CrossRef]

62. Pavlou, P.A.; Liang, H.; Xue, Y. Understanding and mitigating uncertainty in online exchange relationships: A principal-agent perspective. MIS Q. 2007, 31, 105-136. [CrossRef]

63. Podsakoff, P.M.; MacKenzie, S.B.; Podsakoff, N.P. Sources of method bias in social science research and recommendations on how to control it. Annu. Rev. Psychol. 2012, 63, 539-569. [CrossRef] [PubMed]

64. Carmeli, A.; Dutton, J.E.; Hardin, A.E. Respect as an engine for new ideas: Linking respectful engagement, relational information processing and creativity among employees and teams. Hum. Relat. 2015, 68, 1021-1047. [CrossRef]

65. Du, Y.; Zhang, L.; Chen, Y. From creative process engagement to performance: Bidirectional support. Leadersh. Organ. Dev. J. 2016, 37, 966-982. [CrossRef]

66. Zhang, Y.; Begley, T.M. Perceived organisational climate, knowledge transfer and innovation in China-based research and development companies. Int. J. Hum. Res. Manag. 2011, 22, 34-56. [CrossRef]

67. Podsakoff, P.M.; MacKenzie, S.B.; Bommer, W.H. Transformational leader behaviors and substitutes for leadership as determinants of employee satisfaction, commitment, trust, and organizational citizenship behaviors. J. Manag. 1996, 22, 259-298. [CrossRef]

68. Parker, S.K.; Williams, H.M.; Turner, N. Modeling the antecedents of proactive behavior at work. J. Appl. Psychol. 2006, 91, 636-652. [CrossRef]

69. Hair, J.F., Jr.; Hult, G.T.M.; Ringle, C.M.; Sarstedt, M. A Primer on Partial Least Squares Structural Equation Modeling (PLS-SEM); SAGE Publications, Inc.: Thousand Oaks, CA, USA, 2014.

70. Souto, J.E. Business model innovation and business concept innovation as the context of incremental innovation and radical innovation. Tourism Manag. 2015, 51, 142-155. [CrossRef]

71. Ringle, C.M.; Wende, S.; Will, A. SmartPLS 2; SmartPLS: Hamburg, Germany, 2005.

72. Zikmund, W.G.; Babin, B.J. Exploring Marketing Research, 9th ed.; Thomson South-Western: Mason, OH, USA, 2007.

73. Urbach, N.; Ahlemann, F. Structural equation modeling in information systems research using partial least squares. J. Inf. Technol. Theory Appl. 2010, 11, 5-40.

74. Fan, L.; Mahmood, M.; Uddin, M.A. Supportive Chinese supervisor, innovative international students: A social exchange theory perspective. Asia Pac. Educ. Rev. 2019, 20, 101-115. [CrossRef]

75. Cohen, J. Statistical Power Analysis for the Behavioral Sciences; Academic Press: New York, NY, USA, 1977. 
76. Hair, J.F., Jr.; Hult, G.T.M.; Ringle, C.M.; Sarstedt, M. A Primer on Partial Least Squares Structural Equation Modeling (PLS-SEM); SAGE Publications, Inc.: Thousand Oaks, CA, USA, 2017.

77. Tenenhaus, M.; Vinzi, V.E.; Chatelin, Y.-M.; Lauro, C. PLS path modeling. Comput. Stat. Data Anal. 2005, 48, 159-205. [CrossRef]

78. Cohen, J. Statistical Power Analysis for the Behavioral Sciences; Lawrence Erlbaum Associates: Hillsdale, NJ, USA, 1988.

79. Wetzels, M.; Odekerken-Schröder, G.; Van Oppen, C. Using PLS path modeling for assessing hierarchical construct models: Guidelines and empirical illustration. MIS Q. 2009, 33, 177-195. [CrossRef]

80. Fornell, C.; Larcker, D.F. Evaluating Structural Equation Models with Unobservable Variables and Measurement Error. J. Mark. Res. 1981, 18, 39-50. [CrossRef]

81. Chou, J.-S.; Yeh, C.-P. Influential constructs, mediating effects, and moderating effects on operations performance of high speed rail from passenger perspective. Transp. Policy 2013, 30, 207-219. [CrossRef]

82. Hayes, A.F. Introduction to Mediation, Moderation, and Conditional Process Analysis: A Regression-Based Approach; The Guilford Press: New York, NY, USA, 2013.

83. Baron, R.M.; Kenny, D.A. The moderator-mediator variable distinction in social psychological research: Conceptual, strategic, and statistical considerations. J. Pers. Social Psychol. 1986, 51, 1173-1182. [CrossRef]

84. Sobel, M.E. Asymptotic confidence intervals for indirect effects in structural equation models. Sociol. Methodol. 1982, 13, 290-312. [CrossRef]

85. Soper, D.S. Sobel Test Calculator for the Significance of Mediation [Software]. 2017. Available online: https://www.danielsoper.com/statcalc/calculator.aspx?id=31 (accessed on 27 April 2019).

86. Den Hartog, D.N.; Belschak, F.D. When does transformational leadership enhance employee proactive behavior? The role of autonomy and role breadth self-efficacy. J. Appl. Psychol. 2012, 97, 194-202. [CrossRef]

87. Deluga, R.J. American presidential proactivity, charismatic leadership, and rated performance. Leadersh. $Q$. 1998, 9, 265-291. [CrossRef]

88. Parker, S.K. Enhancing role breadth self-efficacy: The roles of job enrichment and other organizational interventions. J. Appl. Psychol. 1998, 83, 835-852. [CrossRef]

89. Crant, J.M.; Bateman, T.S. Charismatic leadership viewed from above: The impact of proactive personality. J. Organiz. Behav. 2000, 21, 63-75. [CrossRef]

90. Zennouche, M.; Zhang, J.; Wang, B.W. Factors influencing innovation at individual, group and organisational levels: a content analysis. Int. J. Inf. Syst. Chang. Manag. 2014, 7, 23-42. [CrossRef]

91. Baer, M.; Oldham, G.R.; Cummings, A. Rewarding creativity: when does it really matter? Leadersh. Q. 2003, 14, 569-586. [CrossRef]

92. Anderson, N.; Potočnik, K.; Zhou, J. Innovation and creativity in organizations a state-of-the-science review, prospective commentary, and guiding framework. J. Manag. 2014, 40, 1297-1333. [CrossRef]

93. Woodman, R.W.; Sawyer, J.E.; Griffin, R.W. Toward a theory of organizational creativity. Acad. Manag. Rev. 1993, 18, 293-321. [CrossRef]

94. Woodman, R.W.; Schoenfeldt, L.F. An interactionist model of creative behavior. J. Creat. Behav. 1990, 24, 10-20. [CrossRef]

95. Edmondson, A.C.; Mogelof, J.P. Explaining psychological safety in innovation teams: organizational culture, team dynamics, or personality. In Creativity and Innovation in Organizational Teams; Lawrence Erlbaum Associates: Mahwah, NJ, USA, 2006; pp. 109-136.

96. Edmondson, A.C. Psychological safety and learning behavior in work teams. Adm. Sci. Q. 1999, 44, 350-383. [CrossRef]

97. Carmeli, A.; Reiter-Palmon, R.; Ziv, E. Inclusive leadership and employee involvement in creative tasks in the workplace: The mediating role of psychological safety. Creat. Res. J. 2010, 22, 250-260. [CrossRef]

98. Vaccaro, I.G.; Jansen, J.J.P.; Van Den Bosch, F.A.J.; Volberda, H.W. Management innovation and leadership: The moderating role of organizational size. J. Manag. Stud. 2012, 49, 28-51. [CrossRef]

99. Hofstede, G. Think Locally, Act Globally: Cultural Constraints in Personnel Management. Manag. Int. Rev. 1998, 38, 7-26. [CrossRef]

(C) 2019 by the authors. Licensee MDPI, Basel, Switzerland. This article is an open access article distributed under the terms and conditions of the Creative Commons Attribution (CC BY) license (http://creativecommons.org/licenses/by/4.0/). 